\title{
ALGUMAS CONSIDERAÇÕES EM TÔRNO DO COLÓQUIO DE HISTÓRIA MARÍTIMA REALIZADO EM PARIS EM 1956.
}

Com o título, Le Navire et l'Économie Maritime du XVe au XVIIIe Siècles, foram publicados em Paris, em 1957, com o concurso do Centre National de la recherche scien'ifique, os trabalhos apresentados ao colóquio de história marítima realizado a 17 de maio de 1956 na Académie de Marine, coordenados pelo professor Michel Mollat com a colaboração de Oliver de Prat.

Os trabalhos apresentados nesse colóquio, em número de sete, foram os seguintes: Le bâtiment de commerce et la navigation après les grandes découvertes, pelo comandante Denoix; Les constructions navales a Bordeax d'après les archives notariales du XVIe siècle, pelo professor Jacques Bernard; Les graffiti dieppois-etudes de types de navires de la Manche, pelo magistrado Henti Cahingt; La tonelada espagnole aux XVIe et XVIIe siècles, pelo professor Pierre Chaunu; Jauge et tonnage des navires, pelo engenheiro Paul Gille; Les origines de la navigation astronomique aux XIV et XVe siècles, pelos professôres Guy Beaujouan e Emmanuel Poulle; Où en est l'histoire du navire, pelo comandante Guilleax la Roerie. Fecha o livro uma alocução do brilhante historiador Lucien Febvre, recentemente falecido. Como se vê, as comunicações feitas ao colóquio e que foram tôdas submetidas a debates, são de capital importância para os que, como nós, se dedicam ao estudo da história dos descobrimentos marítimos.

A maior parte dessas comunicações abordam questões de ordem técnicas sôbre construções navais e assuntos correlatos, como tipos de embarcações, tonelagens, etc., que escapam à nossa competência. Todavia, da leitura atenta qu 2 fizemos do livro, aprendemos muitas coisas e também verificamos que, o pouco que temos escrito sôbre o assunto em tela, está plenamente apoiado pelos eruditos professôres que participaram dêsse colóquio.

O trabalho do comandante Denoix intitulado Le bâtiment de commerce $a^{4}$ la navigation après les grandes décourvertes, é muito interessante e traz alguns proveitosos ensinamentos sôbre a navegação dos normandos. Apesar de admitirmos a possibilidade dos 
normandos terem, nos séculos $\mathrm{X}$ e XI, atingido uma parte da América Setentrional, sempre duvidamos que nessas navegações tenham êles usado os drakars (dragões), tanto assim que escrevemos (1):

"Os drakars tinham os seguintes caracteristicos: comprimento de 25 a 27 metros; bôca de 5 a 6 metros; pontal 1 e meio a 1 metro e 70 centímetros; em cada lado 15 remos e um mastro central com vela quadrada. Devido a ser pequeno o pontal, ficava mui reduzido o espaço disponivel para o transporte de alimentos e água para a tripulação calculada entre 60 a 80 homens. Portanto, navios de pequena autonomia, tanto assim que não dispunham de coberta para abrigar as tripulações das intempéries".

Agora notamos, na referida comunicação do comandante Denoix, êste tópico bastante interessante e elucidativo, que justifica plenamente a nossa opinião de que não foram com os drakars que os normandos realizaram as suas viagens ao Novo Mundo, mas sim com outro tipo de navio. Diz o comandante Denoix o seguinte:

"Dans les mers du Nord, le drakar remplace la galère; c'est comme elle un pirate côtier, fait pour naviguer en eaux calmes et en rivière. Sa quille n'est pas un plan de dérive ou une pièce principale de sa charpente; elle semble beaucoup plus destinée à permettre de rouler a1sément le navire et nous savons que les Normands remontant la Seine passaient par la terre dès qu'il rencontraint un obstacle. Traverser l'Atlantique avec un drakar reconstitué a été essayé de nos jours et, si l'expérience a réussi une fois, elle s'est terminée la seconde par un naufrage corps et biens, et, pourtant, un drakar moderne était sûremant mieux construit que le modèle antique. Pour défandre leurs nefs, Nordiques et Hanséates devaient se grouper et embarquer des équipages surabondants, rendant leurs transports onéreux et difficiles. Il ne semble pas qu'ils aient recheché comme en Méditerranée l'escorte de bâtiments de combat spécialisés”.

Refere-se ligeiramente o comandante Denoix aos processos então usados para medir alturas pela observação do sol na sua culminância e da estrêla polar. Aludindo à longitude, diz que no século XV ela era obtida pelas observações dos satélites de Júpiter e pelas eclipses, isso em terra, porque no mar, êsses processos eram impraticáveis. Diz mais, que nos meados do século XVIII, foi usado

(1). - Revista de História, número 26, abril-junho de 1956, página 269. 
o método das distâncias lunares e que só no fim dêste século é que foram obtidos resultados precisos, devido aos cronômetros de precisão.

Pedimos permissão para dizer aqui, que o comandante Denoix esqueceu-se de nos contar que o primeiro ensaio para calcular longitude por meio das distâncias lunares e das ocultações de planetas foi feito por Vespucci na noite de 23 de agôsto de 1499 . E' verdade que com os cronômetros aperfeiçoados, podia-se determinar isoladamente a latitude e a longitude, mas isso não satisfazia os nautas que desejavam obter a verdadeira efetivação prática do ponto do mar, simultâneamente das duas ordenadas, o que ocorreu em 1837, quando o capitão norte-amerciano Sumner, descobriu as curvas e as retas de altura (2).

Ao ser discutida a comunicação em apreço, o almirante Lepotier perguntou ao comandante Denoix com que tipo de navio os normandos teriam atingido a Islândia, Groenlândia e até a América, se os drakars não eram navios de alto mar? $\mathrm{O}$ comandante Denoix respondeu que, para as viagens ao longo das costas e para as expedições de pirataria na Normândia, é verdade que frotas importantes de drakars com equipagens numerosas, foram organizadas. Porém para a Groenlândia não se realizaram grandes expedições e os navios empregados do século $\mathbf{X}$ ao XIV, eram de tipos que são encontrados em todos os mares do Norte, com casco clássico para navegar em alto mar. $O$ almirante Lepotier declara que Erik-o-Ruivo, partiu da Islândia para a Groenlândia com os primeiros povoadores e, pelo menos, com diversas dúzias de navios carregados de mulheres e crianças. O comandante Denoix diz que não acredita que êsses navios fôssem os drakars, pois que Erik viveu no século $X$ e já nessa época o drakar era embarcação antiqüada. $\mathbf{E}$ acrescenta: as sagas foram escritas a partir do século XIII e, nessa época, o drakar tinha adquirido na lenda tal importância, que substituia outro navio, se bem que êste parece não ter existido.

Participando dos debates, o professor Pierre Chaunu disse que pelo Tratado de Tordesillas, a linha de demarcação passava a 1600 mitunas a oeste dos Açores, quando em realidade passava a 370 lésuas da ilha mais a oeste do arquipélago de Cabo Verde.

Outros assuntos bastante interessantes foram debatidos, inclusive aquêle referente aos navios usados pela Liga Hanseática e pelos venezianos.

*s

(2). - A Fontoura da Costa, A Marinharia dos Descobrimentos, Lisboa, 1939, página 149. 
Os trabalhos dos professôres Guy Beaujouan e Emmanuel Poulle, sôbre as origens da navegação astronômica nos séculos XIV e $\mathrm{XV}$, são aquêles que mais apreciamos, por estarmos mais familiarizados com os assuntos que ventilaram.

Após citar os mais recentes livros publicados sôbre a questão em tela, o professor Beaujouan passa a apreciar a tese do historiador espanhol Gonzalo Reparaz que atribui aos catalães a prioridade da navegação astronômica pelos seguintes motivos: os relatos dos reis de Aragão do século XIV fazem numerosas referências aos astrolábios; na mesma época, na escola cartográfica catalã-maiorquina surgem verdadeiras obras primas, como o Atlas de Carlos V; mais ou menos em 1420, o infante D. Henrique de Portugal mandou vir de Maiorca um certo mestre de nome Jácomo, filho do judeu maiorquino Abraham Cresques, versado na arte de navegar e fabricante de cartas e instrumentos náuticos.

Acontece, porém, que o professor Beaujouan apresenta a essa tese diversas objeções, a saber: primeiro, que há uma forte tendência para esquecer que se a Catalunha foi no século XIV um centro de intensa atividade marítima e cartográfica, por sua vez nenhuma outra região da Europa, como ela, adiantou-se tanto no que diz respeito às doutrinas esotéricas e à astrologia divinatória. Assim, pois, os astrolábios não eram usados para navegar, porém para obtenção de horóscopos; segundo, que as cartas marítimas catalãs não permitiam a determinação imediata das coordenadas geográficas de um ponto dado, portanto a navegação foi simplesmente empírica e o seu desenvolvimento não teve, nessa época, nenhuma relação com as preocupações científicas das Universidades medievais .

Passa a seguir o professor Beaujouan a considerar a possibilidade dessa prioridade pertencer aos nautas portuguêses, mas antes de abordar o assunto, faz notar que neste caso existe um problema metodológico dos mais difíceis, como aquêle da "política de sigilo" dos monarcas portuguêses, pois que, quem diz sigilo, diz em realidade ausência de documentos.

O referido professor começa por fazer referência a um trabalho da autoria do professor português Armando Cortesão, editado em Coimbra em 1954, escrito em inglês, intitulado The nautical chart of 1424 and the early discovery and cartography of America, onde o seu autor sustenta que, antes de 1424, os portuguêses já conheciam as Antilhas e que, devido aos ventos e correntes marítimas, a viagem para êsse ponto era fácil, pelo que se pode admitir que até os fenícios, nas suas navegações, também tenham atingido a América.

Contestando essa temerária opinião de Armando Cortesão, diz textualmente o professor Beaujouan o seguinte: 
"M. Cortesão a eu le courage de ne pas s'arrêter en chemin: il nous rappelle ainsi la fragilité de ses prémisses. Plus encore que l'historien des découvertes géographiques, celui de l'astronomie nautique risque de cédre à la psychose du secret et aux facilités trompeuses du manque de documents".

Nesta Revista (3) já tivemos o ensejo de resumidamente nos ocuparmos do referido trabalho do professor Armando Cortesão, provando a inconsistência da sua tese, pois que a carta náutica de 1424 a que se refere, ora na Biblioteca da Universidade de Minnesota, é em tudo semelhante aos demais mapas medievais que reproduziam todo o sistema geográfico da Antigüidade, inclusive o dos tempos homéricos; as idéias de Aristóteles, Platão, Estrabão, Sêneca, Ptolomeu e outros sábios, bem como as lendas antigas e as religiosas da Idade Média, inclusive aquela referente a Ilha das Sete Cidades ou Antilha, isso devido a que os cartógrafos daquela época se limitavam a copiar as antigas cartas, assinalando nas suas, sem o menor escrúpulo, tudo o que nelas encontravam. Em resumo: a cartografia era sistemática.

Prosseguindo na sua comunicação ao colóquio, o professor Beaujouan refere-se a um estudo do historiador português Antônio Barbosa, intitulado Novos subsídios da ciência náutica portuguêsa da época dos descobrimentos, publicado em 1948 na cidade do Pôrto, que qualifica de sedutor à primeira vista, pois que para êste historiador, depois do segundo quartel do século $\mathrm{XV}$, os portuguêses navegavam determinando a latitude pela altura da polar, evitando assim as dificuldades inerentes ao emprêgo da tábua das declinações solares. Porém os veleiros que na ida navegavam acompanhando as costas africanas, deviam na volta se afastar. Quando os portuguêses em 1471 passaram a equinocial, deixaram desde então de observar a estrêla polar e recorreram às tábuas apropriadas para calcular a altura do sol, sendo que êste novo processo teria sido adotado entre 1480 a 1485 .

Já tivemos o ensejo de provar (4) que a volta pelo sargaço a que se refere Antônio Barbosa, foi brilhantemente constestada pelo capitão de mar e guerra da marinha de guerra portuguêsa, Quirino da Fonseca, membro da Academia das Ciências de Lisboa (5). Convém acrescentar, como mui judiciosamente diz o professor Beaujouan, que "todo êsse edifício", de Barbosa tem por base uma referência muito posterior às datas indicadas, feita pelo historiador português João de Barros.

(3). - Revista de História, número 26, abril-junho de 1956, página 296 a 300.

(4). - Revista de Históría, número 19, julho- setembro de 1954, páginas 213 e 214.

(5). - Quirino da Fonseca, A Caravela Portuguêsa, Coimbra, 1934, páginas 221 a 224. 
Alude o professor Beaujouan ao que diz o almirante Gago Coutinho: os nautas portuguêses determinavam a latitude, a bordo, pelo estrêla polar; desde o tempo do infante D. Henrique, tomavam, no mar, a altura do sol:

Acontece, porém, que os fatos devidamente documentos contrariam essas afirmativas de Gago Coutinho e provam que, mesmo no fim do século XV e comêço do XVI, os portuguêses não caIculavam latitude a bordo, no mar, mas sim em terra. Em novembro de 1497, na angra de Santa Helena, em terra, Vasco da Gama observou o sol com o astrolábio (6). Na carta que, de Pôrto Seguro, a $1 .^{\circ}$ de maio de 1500 , escreveu Mestre João ao rei D. Manuel, diz que calculou a latitude dêsse lugar estando em terra, e justifica porque assim procedeu dizendo textualmente:

“... solamente mando a vosa alteza como estan situadas las estrellas del, pero en que grrado esta cada una non lo he podido saber, antes me paresce ser inposibele en la mar tomarse altura de ninguna estrella porque yo trabaje mucho en eso e por poco que el nauio enbalance se yerran quatro, o cinco grrados, de guisa que se non puede fazer synon en terra..." (7).

Fica-se verdadeiramente indeciso quando se procura estabetecer a data certa em que os nautas portuguêses iniciaram a verdadeira navegaçäo astronômica, uma vez que calcular latitude em terra, em absoluto não é astronomia náutica. Aliás o professor Beaujouan diz com muito acerto que o processo de determinar latitude em terra, era patrimônio comum de todos os astrônomos dos séculos $\mathrm{XIV}$ e XV, não havendo portanto nem novidade nem sigilo.

*

Bastante interessante também, o trabalho do professor Emmanuel Poulle sôbre o emprêgo dos instrumentos astronômicos nas navegações do século $X V$. O seu estudo é um complemento àquêle do professor Beaujouan.

Poule, de início, refere-se à grande confusão que existe com referência ao astrolábio, pois que na Idade Média a palavra astro. labiurn designava diversas coisas umas muito diferentes das outras. A imprecisão dos têrmos era ainda ma1or, quando falavam do quadrante, visto que êste vocábulo era usado para indicar todo e qualquer instrumento com a forma de um quarto de disco. Com êsse nome designavam o quadrans retustissimus do século $\mathbf{X}, 0$

(6). - Joáo de Barros, Da Ásia, Lisboa, 1778-1788, dêcada I, livro IV, capít'œe II.

(7). - A. Fontoura da Costa, obra citada, página 120. 
quadrans vertus do XII, e o quadrans novus do século XIII. Os dois primeiros eram horários e geométricos, e o último destinado a resolver problemas astronômicos. Os instrumentos que podiam existir a bordo eram de quatro tipos: o astrolábio e seus derivados (quadrans novus), os quadrantes (sobretudo quadrans vetus), o instrumento que pertenceu a Nicolas de Cues e a balestilha, também conhecido por Báculo de São Tiago. Uma vez que êste último instrumento, como diz Paulle, era mais indicado para medir o ângulo de duas estrêlas, que para determinar a altura de uma estrêla sôbre o horizonte, devido a dificuldade que existia de, sôbre o mar, visar acertadamente êste último; não tendo sido fabricado o instrumento de Nicolas de Cues, restavam o quadrante e o astrolábio, que uma tradição bastante antiga chamava de instrumentos de navegação, devido a confusão termonológica que Poulle agora assinala, pois que o astrolábio astronômico é um, e o astrolábio náutico é outro, sendo que êste último não aparece a não ser nos primeiros anos do século XVI. A primeira menção do astrolábio náutico foi feita por meio de desênho num mapa existente na Biblioteca do Vaticano e datado de 1529. Diz Poulle que é possível que a invenção seja de data anterior, uma vez que não é muito difícil passar do astrolábio astronômico, muito complicado, para o náutico.

Poulle faz referência ao estudo de Anthiaume \& Sottos ( $L$ 'Astrolabe-quadrant du Musée des Antiquités de Rouen, Paris, 1910), para contestar servir êsse aparêlho para indicar as marés e, conseqüentemente, a sua utilidade na náutica. E acrescenta: todos os tratados medievais sôbre o astrolábio existentes em França, não fazem. a menor alusão ao seu emprêgo na náutica, porém, sim, na geografia, para determinar a diferença de longitude entre duas cidades por meio da observação de um eclipse da Lua, diferença de latitude, etc. O que necessita ficar bem claro, diz o professor Poulle, é que não havia segrêdo a esconder, visto que as soluções para determinar latitude pela altura meridiana do sol, ou pela altura da polar, eram encontradas em todos os manuais de astronomia. Acrescentamos nós: os portuguêses conheciam os Libros de saber de Astronomia do rei Afonso $\mathbf{X}$ de Castela, e nesses livros existem os ensinamentos para calcular latitude de um lugar, tanto pela polar, como pela declinação do sol.

Nas suas explanações visando provar a insegurança das medidas de latitude tomadas no mar, nos relata o que ocorreu em abril de 1500 em Pôrto Seguro com quem mediu alturas das estrêlas do hemisfério austral. Mas assim procedendo, comete um eqüívoco, atribuindo isso ao pilôto cientista português João de Castro, quan- 
do em realidade quem tomou as medidas foi Mestre João. Cita o testemunho de Pedro Nunes que, descrevendo em 1533 os instrumentos de medir altura, quando já tinha sido substituído o fio de chumbo do quadrante por uma régua um pouco menos sensivel, se queixava da incerteza das medidas, cuja precisão, apesar do cuidado com que o aparêlho foi fabricado, não podia, na sua opinião, exceder o grau.

Dizendo fazer tábua rasa de qualquer preconceito, o professor Poulle diz chegar a dois fatos comprovados a saber: primeiro, a importância das observaçóes terrestres ao longo da costa ocidental da África pelos portuguêses. E' o caso dos astronômos descerem em terra para fazer as suas observações e depois voltarem aos navios, como fêz Vasco da Gama na angra de Santa Helena em 1497 e Mestre João em Pôrto Seguro em 1500. Estas observações terrestres, insiste o professor Poulle, não podem ser tachadas de navegação astronômica, pois que elas não diferenciam daquelas feitas, não importa em que cidade da Europa, por um astrônomo de nome Rodolfo de Bruges, tomando a 24 de abril de 1154, a latitude de Barcelona, por Henrique Bate colocando a $51^{\circ}$ e 18 minutos Malines e outros. Segundo, a inutilidade da determinação da latitude em pleno mar, uma vez que as cartas planas não estavam então em uso.

Termina o professor Poulle a sua comunicação, referindo-se a pretensa observação astronômica de Diogo Gomes, mais ou menos em 1463, na Guiné. Não merece ser tomado em consideração tal observação, pois que ela não tem nenhum mérito para o estudo da astronomia náutica (8).

Ao ser debatida a comunicação do professor Poulle, o professor Mauro disse que, na sua opinião, o grande problema é aquêle do uso das tábuas de navegação. E pergunta: a partir de que data essas tábuas foram feitas?

Podemos responder essa pergunta. As tábuas foram feitas por João Müller, mais conhecido por Regiomonte, e pelo judeu Abraham Zacuto. Regiomonte publicou as suas Ephemerides em 1474 e Zacuto escreveu o seu Almanach perpetuum entre 1473 a 1478 . Em 1496, José Vizinho traduziu do hebraico para o latim essa obra de Zacuto. Mas as tábuas existentes nessas duas obras, não eram de fácil manêjo pelos pilotos, pelo que tiveram necessidade de adaptálas ao uso dêstes. Conhecemos o Regimento do estrolábio e do quadrante, mais conhecido como Regimento ou Manual de Munique, publicado mais ou menos em 1509, embora os historiadores portuguêses afirmem que êle foi mantido em sigilo até a data ora refe-

(8). - Duarte Leite, Lendas na histótia da navegação astronômica em Portugal, Coimbra, 1950, Biblas, XXVI, páginas $413-430$. 
rida. Além dêsse Regimento, existiam outros, como o de Evora de 1519. Acontece, porém, que o professor Poulle, nos debates, disse que os portuguêses fazem alarde a respeito dos Regimentos, mas que êles não trouxeram, sob o ponto de vista científico, nada de novidade. $\mathbf{E} \circ$ professor Beaujouan acrescentou que o fato original que os Regimentos apresentam é, não as tábuas em si, mas o modo de se aplicar à navegação os conhecimentos de há muito tempo divulgados no Ocidente.

Por ter íntima relação com as comunciações feitas pelos professôres Guy Beaujouan e Emmanuel Poulle, ao colóquio realizado em Paris em 1956, sôbre as origens da navegação astronômica nos séculos XIV e XV, transcrevemos aqui, devidamente traduzido para o vernáculo, um interessante estudo de Alberto Magnaghi (9), professor da Universidade de Palermo, referente à tábua das declinações solares para a determinação das latitudes em alto mar.

\begin{abstract}
" $E$ agora se apresenta, com relação a tudo isso, uma grande questão: a quem e em que proporção, pertence o mérito de ter organizado e aplicado a tábua das declinações solares para a determinação das latitudes nas viagens em alto mar. Também aqui vemos entrar em choque o amor próprio nacional: dos portuguêses de um lado e dos alemães de outro. Uma tradição, de há muito conhecida, admitia até bem pouco tempo que a tábua se encontrava na Ephemerides de Regiomonte (publicada em 1474 e calculada para os anos de 1475-1506). Porém há vários anos o erudito português Joaquim Bensaúde constatou que esta obra do astrônomo de Nuremberg, que Martim Behaim introduziu em Portugal, não contém a tábua das declinações solares. Bensaúde que tratou a fundo do assunto, repetiu êste argumento várias vêzes animado - talvez em demasia - com obietivo de exaltar a inddependência da ciência da Península Ibérica de modo geral e da de Portugal de modo especial, daquela alemã do Renascimento. Os portuguêses, ao invés teriam encontrado esta tábua das declinações solares e outras necessárias para a navegação astronômica na obra de Abrão Zacuto, publicada, é verdade, só em 1496 em Leiria, mas - diz Bensaúde - desde vários anos circulando manuscrita na Península Ibérica (desejam, dizemos desde já, arranjar as coisas de modo que essa tábua tenha servido de base para os trabalhos da famosa "Junta" reunida não depois de 1485). E o Sr. Lallemand (Charles Lallemand), "Les services rendus par le Portugal aux sciences géographiques",
\end{abstract}

(9). - Una curiosa documentazione dei servigi resi dal Portogallo alle scienze geografiche nell'epoca delle grandi scoperte. "Revista Geográfica Italiana", Firenze, 1934, fascículo VI, páginas 160 a 168 . 
“Aannuaire pour l'an 1934, publié par le Bureau des Longitudes", Paris, 1934) se apressa, naturalmente, em aceitar estas conclusões. Depois de ter evidenciado que as Ephemerides de Regiomonte não contém em absoluto a famosa tábua, afirma que "par contre, l'Almanach perpetıllum d'Araban Zacuto redigié à Salamanque em 1473 et dont il existe une édition portugaise (sic) de 1496 contenait pour ce genre de calculs, des tables que l'on trouve reproduites, deux ans plus tard, dans les Ephemerides de Regiomontanus".

"Sem aprofundarmos no exame da questão, o que nos levaria muito longe, mas estudando a questão com um pouco de atenção e sem preconceitos, chega-se à conclusão de que não valia a pena fazer em tôrno dela tanto estardalhaço; porque, em conclusão, a tábua das declinacões antes de tudo se encontra em uma ontra obra de Regiomonte, e em segundo lugar porque antes desta obra, como aquela de Zacuto, era já encontrada em trabalhos de astrônomos árabes".

"Abrahão Zacuto (1450-1510), cuja obra escrita em hebraico, tinha sido traduzida para o latim e publicada como se disse pelo seu discípulo José Vizinho, foi professor de astronomia em Salamanca de 1474 a 1492; e neste ano teve que deixar a Espanha em conseqüência de perseguição religiosa passando a serviço do rei de Portugal. As tábuas que mais interessam são quatro $T a$ bule Solis que dão a longitude geocêntrica ao Sol por quatro anos, três comuns e um bissexto, para cada dia do ano e para cada um dos signos do Zodíaco, ciclo 14731476. A organização do Almanach é a partir de 1473 , porque êste é o ano raiz, do qual se começa a computar o ciclo. Há ainda a famosa Tabula declinationis Solis $a b$ equinoctiali, destinada a indicar a distância em graus e minutos do Sol do Equador para deduzir, subtraindo ou acrescentando êsse ângulo à altura meridiana do Sol em determinado dia, a latitude de um determinado lugar. Este é o grande mérito que Bensaúde atribui a Zacuto, de ter reunido em um só volume os elementos necessários para a determinação das latitudes; ao passo que (Bensaúde grita e repete de modo a ensurdecer) nas $E p h e$ merides de Regiomonte falta o segundo elemento. Porém êle não ignora que êste é encontrado em uma outra obra do astrônomo alemão (Tabula directionum, etc. publicada em 1475). Apesar disso, afirma que os marinheiros para obterem os dados de que necessitavam, deviam possuir os dois trabalhos e saber utilizá-los. Afirmativa, como se vê, bem curiosa: como se fôsse um grande sacrificio consultar os dados fornecidos pelas duas obras. Sem grande trabalho, em meia fôlha de papel podiam copiar a tóbua das declinações e anexá-la às Ephemerides. O que é certo - e admitamos também que em Portugal e alhures esta tábua das declinações fôsse conhecida muito antes que impressa a obra de Regiomonte - é que tinha 
sido impressa 21 anos antes da publicação da obra de Zacuto. Se êste a obteve da obra manuscrita, não sabemos; mas de qualquer modo o mérito não seria tão grande, dado o fato que (veremos mais adiante) a tábua era conhecida havia alguns séculos. Mas para evitar que alguém possa supor ter Zacuto recorrido à obra do astrônomo alemão para a publicação de sua tábua, Bensaúde (Les Legendes, etc. vol. II, pág. 174) grita triunfante que ao passo que para Regiomonte a máxima declinação é de $23^{\circ}$ e $30^{\prime}$ para Zacuto é de $23^{\circ}$ e $33^{\prime}$. Dêsse modo não percebe que êste último se limita a copiar um dado conhecido havia cêrca de dois séculos, ao passo que Regiomonte apresenta elemento correto baseado em suas próprias observações e que corresponde à verdade".

"Com relação ao mérito que se queira dar a Zacuto pela publicação da tábua das dectinações e a possibilidade que essa obra tenha sido utilizada quando manuscrita, é oportuno esclarecer que a famosa tábua é encontrada nas notas manuscritas de Colombo em uma fôlha de guarda do exemplar do "Imago Mundi" de sua propriedade. Também para Colombo, como para Zacuto e outros anteriores e posteriores, a inclinação da Eclitica, isto é, a declinação máxima do Sol é de $23^{\circ}$ e $33^{\prime}$. Mas não dizem que Colombo tenha copiado essa tábua de Zacuto. Nós não sabemos quando êle escreveu as suas notas; provàvelmente entre 1488 e 1491, em todo o caso antes que fôsse publicada a obra de Zacuto (1496). Ora, se cópias de Zacuto circulavam manuscritas, essas eram em hebraico, porque a primeira tradução em latim é precisamente aquela do seu dicípulo Vizinho publicada em 1496. E como Colombo não sabia hebraico, segue-se que copiou a tábua de qualquer manuscrito latino; e êste podia já de algum tempo circular na Península Ibérica e por tôda a parte".

"Sabemos, porém, com certeza, que o próprio Zacuto derivava os seus conhecimentos astronômicos de uma velha tradição que, transmitida pelos hebreus, remonta aos árabes e quase seguramente aos gregos. E também Zacuto - é de se acrescentar — não intencionava em realidade escrever um tratado destinado a usos positivamente práticos por exemplo, para a gente do mar. Ele pertencia àquela estirpe de astrólogos, na maioria hebreus, que na Idade Média se dedicaram com paixão a procurar nos movimentos dos astros o segrêdo dos destinos humanos. Ora, em Montpellier existe um tratado do quadrante composto mais ou menos en 1292 e, nessa obra, são encontradas uma tábua das declinações solares e quatro tábuas, em graus e minutos com a longitude do Sol dia por dia para um ciclo de 4 anos; e de acôrdo com essas tábuas foram organizadas dois séculos depois as de Zacuto. Além disso Zacuto conserva o ângulo da Eclítica de $23^{\circ}$ e $33^{\prime}$. $\mathrm{E}$ o autor dêste tratado também procura saber qual tenha sido a sua fonte no que diz respeito a tabula declinacionis; 
e diz que segundo Al-Battani, o grande astrônomo árabe (856-929), cuja obra foi profundamente estudada por Carolo Alphonso Nallino, "All Battini sine Abatenii opus astronomicum"... Milão, 1907. Desta derivam em substância também as famosas Tábuas Afonsinas do século XIII que, além da "Tabla de la declinacion del Sol", contém quatro tábuas das longitudes solares para o usual ciclo de quatro anos, e derivam do mesmo modo tôdas as obras manuscritas das quais nos fornece Bensaúde um grande catálogo".

"Mas com tudo isso os portuguêses nada têm que ver, pois que antes da publicação em Leiria em 1496 do Almanach perpetuum de Zacuto, não existe nada que nos leve a admitir gue êles tenham trazido uma direta e eficaz contribuiçâao ao progresso da aplicação da astronomia nántica. Verdade é que Bensaúde diz que todos êsses escritores são representantes das sciences peninsulaires, mas eram hebreus que agora são elevados à categoria de representantes das referidas sciences como pertencentes ao penples iberiques, o que não ocorria na época em que viveram. E alguma coisa soube Zacuto que, depois de ter- fugido de Salamanca para Portugal, após algum tempo abandonou êste pais e seguiu para Tunes e, finalmente para Salônica, a fim de evitar um tratamento... muito caloroso da Inquisição".

"O mais antigo e até hoje o único documento que revela uma ação concreta dos portuguêses com relação a trabalhos de astronomia náutica, continua sempre a ser a narração de Barros sôbre o encargo dado por D. João II à famosa "Junta" que, de qualquer modo, devia ter-se reunido na segunda metade de 1485 , porque um dos seus membros, José Vizinho, em março dêsse ano estava nas costas de Guiné. Se neste data, e como resultado dos traballos da "Junta" se deve atribuir o famoso folheto conservado na Biblioteca Real de Munique e publicado por Bensaúde: "Regimento do astrolábio $e$ do quadrante para saber ha declinaçam $e$ ho logar do soll em cada huum dia a asy pera saber ha estrella do norte", fica ainda por demonstrar, apesar de Bensaúde estar inclinado a dar isso como certo. Mas mesmo que assim seja, não se trata de grande coisa".

"Mas para voltar a Zacuto e demonstrar que a sua obra não assinalou aquêle progresso que querem hoje os historiadores portuguêses e afins, pode-se citar o fato que Nunes na sua clássica obra (1546) não menciona nunca Zacuto nem Vizinho, ao passo que a todo o momento cita os nomes de Campana, Cardano, Marco Beneventano, Oronzio Fineo e, sobretudo os alemães Werner, Walther, Stoeffer, Peurbach e especialmente Regiomonte".

"E assim sem querer fomos além do que desejávamos ao contestar as afirmativas do $\mathrm{Sr}$. Lallemand no que con- 
cerne à prioridade e à independência da ciência náutica portuguêsa; mas é bom repetir que os famosos elementos calculados por Zacuto, as quatro tábuas das longitudes do Sol para o ciclo de quatro anos e a tábua das declinações, eram em realidade conhecidas havia séculos e eram de procedência árabe".

Encerrando o colóquio, o professor Lucien Febvre, recentemente falecido, numa alocução, de início pergunta se existe uma economia marítima e responde que sim, de amplitude verdadeiramente muito grande, pois que ela comporta antes de tudo os problemas técnicos que são muitos a serem estudados. Ainda mais, diz o professor Fabvre, existem os problemas portuários e aquêles das rotas, sendo que não devemos cingir o estudo às rotas terrestres. Fala dos caminhos por terra para a China, ou da China para a Europa e das dificuldades para o transporte da sêda e depois põe em relêvo a importância das rotas marítimas e o papel preponderante que o Oceano Índico tem representado na história da humanidade.

Passa a se referir à crítica e manifesta-se apologista idela, mas da crítica sadia, construtiva, e não daquela apaixonada, dizendo textualmente:

"C'est de dissertations critiques, même audacieuses, surtout audacieuse dirai-je, que nous avons besoin ici. Non pas que l'audace doive être encouragée pour l'audace: on risque alors de tomber dans ces excès dont nous venons d'entendre faire le procès quand on nous a parlé de l'imagination un peu débordante de certains savants portugais".

Continuado, diz que a experiência de hoje mostra, aos especialistas, que nos quadros das velhas instituições univerșitárias existe já um grande esfôrço da parte da juventude, visando precisamente o estudo dos problemas do mar, da navegação e do comércio marítimo, para cuidar, não simplesmente da história econômica fácil, mas sim da história econômica complicada e difícil, justamente aquela de que há necessidade.

Pertence, pois, aos historiadores, historiadores não especialistas, diz o professor. Febvre, saber reconhecer que uma jornada como a do colóquio prova que, ao lado de historiadores não especialistas, existem homens que têm as mesmas exigências que êstes em se tratando da compreensão, que têm um cuidado de detalhes técnicos infinitamente mais apurados devido a sua formação inicial. 
Esta é a grande lição do colóquio, diz o professor Febvre. Mas torna-se necessário que não fiquemos aqui. E' preciso que esta tradição de colóquios, que reuniu homens que até o presente não tiveram grande contacto uns com os outros, se perpetui. E' necessário procurat criar uma tradição de colaboração, de confraternidade, no sentido mais restrito da palavra.

A alocução do professor Lucien Febvre nos sugere a idéia de instituirmos entre nós, na Universidade de São Paulo e, em particular na Faculdade de Filosofia, Ciências e Letras, os colóquios que se realizaram na França com grande sucesso.

T. O. MARCONDES DE SOUSA

Da Sociedade de Estudos Históricos de São Paulo e da Sociedade dos Americanistas de Paris 